\title{
Parboiled Germinated Brown Rice Decreases Inflammatory Cytokines Levels in Various Regions of Brain in Rats Induced by Carbon Tetrachloride
}

\author{
Kansuda Wunjuntuk ${ }^{1}$, Somsri Chareonkiatkul ${ }^{2}$, \\ and Aikkarach Kettawan ${ }^{2 *}$
}

\begin{abstract}
${ }^{I}$ Department of Home Economics, Faculty of Agriculture, Kasetsart University, Bangkok 10900, Thailand

${ }^{2}$ Food Chemistry Division, Institute of Nutrition, Mahidol University, Nakhon Pathom 73170, Thailand
\end{abstract}

*Corresponding author. E-mail: aikkarach.ket@mahidol.ac.th https://doi.org/10.12982/CMUJNS.2020.0018

\author{
Received: February 6, 2019 \\ Revised: July 12, 2019 \\ Accepted: July 22, 2019
}

\begin{abstract}
Parboiled germinated brown rice (PGBR) from the Khao Dawk Mali 105 (KDML 105) Thai rice strain is well-known for its nutrients and bioactive compounds. This research was conducted to determine the protective effect of PGBR on carbon tetrachloride $\left(\mathrm{CCl}_{4}\right)$-induced brain inflammation. Thirty-five male Sprague-Dawley rats were randomly divided into five groups: (I) control group (basal diet); (II) $\mathrm{CCl}_{4}$ group (basal diet); (III) white rice $+\mathrm{CCl}_{4}$ group; (IV) brown rice $+\mathrm{CCl}_{4}$ group, and (V) $\mathrm{PGBR}+\mathrm{CCl}_{4}$ group. $\mathrm{PGBR}$, brown rice and white rice diets were produced by replacing cornstarch in basal diet with cooked PGBR, brown rice, and white rice, respectively. Twice weekly, each rat was orally administrated with $1 \mathrm{~mL} / \mathrm{kg}$ of $\mathrm{CCl}_{4}$ in olive oil (1:1, v/v). After eight weeks, all rats were subjected to carbon dioxide euthanasia. The cerebral cortex, hippocampus and cerebellum were dissected and homogenised to evaluate the levels of tumour necrosis factor $\alpha(T N F-\alpha)$, interleukin $1 \beta(I L-1 \beta)$, and interleukin 6 (IL-6). It was observed that the administration of $\mathrm{CCl}_{4}$

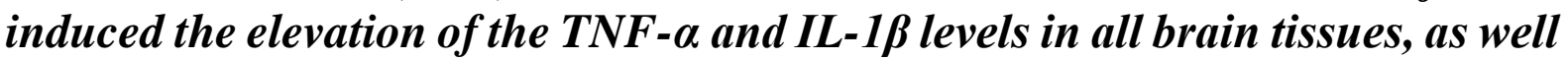
as the blood ammonia and serum liver functions also rose. However, there was a significant reduction in the levels of TNF- $\alpha$ and IL-1及 in the cerebral cortex, hippocampus and cerebellum in the PGBR $+\mathrm{CCl}_{4}$ group compared to the $\mathrm{CCl}_{4}$ group $(P<0.05)$, whereas the blood ammonia and serum liver functions were also decreased. These findings suggest that regular consumption of PGBR may prevent $\mathrm{CCl}_{4}$-induced brain inflammation.
\end{abstract}


Keywords: Brain inflammation, Parboiled germinated brown rice, Carbon tetrachloride, Khao Dawk Mali 105, KDML 105

\section{INTRODUCTION}

Carbon tetrachloride $\left(\mathrm{CCl}_{4}\right)$ is a well- known model for detecting hepatoprotective properties of natural components. In addition, $\mathrm{CCl}_{4}$ causes free radical generation in many bodily tissues; such as the liver, kidney, heart, lung, testis, blood and brain (Dashti et al., 1989). Yamamoto and Sugihara (1987) reported that hyperammonaemia occurred after inducing rats with $\mathrm{CCl}_{4}$ $(1.0 \mathrm{~mL} / \mathrm{kg}$ three times per week for 10 weeks), which was produced by the decrease in the hepatic content and by the inhibition of carbamoyl-phosphate synthetase and arginine-succinate synthetase, important enzymes of the urea cycle. Elevated concentrations of ammonia in the brain as a result of hyperammonaemia resulted in the activation of astrocytes, which stimulated a number of inflammatory signalling systems; such as nitric oxide synthase (NOS), nuclear factor kappa B (NF-kB), and cyclooxygenase-2 (COX-2) (Jayakumar et al., 2006). Additionally, ammonia activates brain microglia, which can release the pro-inflammatory cytokines; such as IL- $1 \alpha$, IL- $1 \beta$ and TNF- $\alpha$ (Atanassov et al., 1994; Rao et al., 2013). Moreover, the hippocampus plays a key role in memory function, particularly the transference from short- to long-term memory and control of spatial memory and behaviour. The cerebral cortex is also a major component of the brain for memory function, as well as attention, perceptual awareness, thought, language and consciousness, while the cerebellum is essential for balance and motor control functions (Preston and Eichenbaum, 2013). Therefore, inflammation in the brain, particularly the hippocampus, cerebral cortex and cerebellum, plays a crucial role in neurodegenerative disorders (Cagnin et al., 2006; Rovira et al., 2007; García Martínez et al., 2010).

Germinated brown rice has numerous bioactive compounds and is renowned for its nutritional components. Several valuable nutrients were remarkably increased after germination, especially increasing 13- fold $\gamma$-oryzanol, 10-fold $\gamma$-aminobutyric acid (GABA), about fourfold dietary fibre, vitamin E, niacin and lysine, and nearly threefold vitamins B1, B6 and magnesium (Kayahara and Tsukahara, 2000). Furthermore, previous studies have shown the anti-oxidant, anti-inflammatory, anti-diabetic and anti-cancer properties in germinated brown rice (Latifah et al., 2010; Zhang et al., 2010; Imam et al., 2012; Soiampornkul et al., 2012). Recently, parboiled germinated brown rice (PGBR) was produced from the Khao Dawk Mali 105 (KDML 105) rice strain, which is the most famous Thai rice, and is known for its texture and aroma. PGBR was produced by steaming germinated paddy rice. During parboiling, starch granules of rice were gelatinised, which improves stability and lessens the rupture 
of the rice grain. The authors' recent reports showed the high quantity of GABA, $\gamma$-tocotrienol, $\gamma$-oryzanol and ferulic acid in PGBR of the Khao Dawk Mali 105 rice, KDML 105 (O. sativa L. cv.) grown in Thailand. In addition, the results showed that PGBR had more anti-fibrotic, anti-inflammatory and antioxidant capacities in rat's liver than brown rice and white rice (Wunjuntuk et al., 2016a; Wunjuntuk et al., 2016b).

Therefore, the purpose of this study was to evaluate the anti-inflammatory effect on the brain of PGBR on the levels of TNF- $\alpha$, IL-1 $\beta$ and IL- 6 in the cerebral cortex, hippocampus and cerebellum of adult rats subjected to an experimental model of $\mathrm{CCl}_{4}$-induced brain inflammation.

\section{MATERIALS AND METHODS}

\section{Animals}

This animal study was approved by the Experimental Animal Care and Use Committee, National Laboratory Animal Centre, Mahidol University (approval no. RA2013-04). A total of 35 male Sprague-Dawley rats weighing 200-250 gram was obtained from The National Laboratory Animal Centre, Mahidol University and maintained in an environmentally controlled room $\left(23 \pm 2{ }^{\circ} \mathrm{C} ; 50 \pm 20 \%\right.$ humidity) with a 12 hour light/dark cycle.

\section{PGBR preparation}

PGBR, brown rice (BR) and white rice (WR) were prepared from the same kind of Khao Dawk Mali 105 (Oryza sativa L. cv., KDML 105) rice grown in Thailand. PGBR was prepared according to the method of Wunjuntuk et al. (2016b). In brief, the paddy rice was soaked in water for 18 hours in an automatic pre-germination machine (Thai patent pending no. 1001000300) and then germinated inside the chamber for about two days. Finally, the germinated rice was steamed for 30 minutes and dehydrated by vacuum drying at $70-75^{\circ} \mathrm{C}$ for two hours. A hot air oven at $40{ }^{\circ} \mathrm{C}$ was then used to dry the steamed rice until the level of moisture content had fallen to $13 \%$.

\section{Animal diets}

Each rice was cooked in an electric rice cooker (1.8 L, Sharp KS-19ET) using the appropriate method (Wunjuntuk et al., 2016a). The cooked rice samples were freeze-dried, ground into fine powder, packed in vacuum-aluminum foil bags and stored at $-20{ }^{\circ} \mathrm{C}$ until used. The cornstarch of AIN76A (basal diet) was replaced with freeze-dried cooked WR, BR and PGBR for preparing the WR, BR and PGBR diets, as shown in Table 1. The contents of WR, BR and PGBR added into the diet were based on the composition of energy, protein, carbohydrate and fat. 
Table 1. Ingredients of basal diet, WR diet, BR diet and PGBR diet formulas.

\begin{tabular}{lcccc}
\hline Formula & $\begin{array}{c}\text { Basal } \\
\text { diet } \\
(\mathbf{g} / \mathbf{k g})\end{array}$ & $\begin{array}{c}\text { WR } \\
\mathbf{d i e t} \\
(\mathbf{g} / \mathbf{k g})\end{array}$ & $\begin{array}{c}\text { BR } \\
\text { diet } \\
(\mathbf{g} / \mathbf{k g})\end{array}$ & $\begin{array}{c}\text { PGBR } \\
\text { diet } \\
(\mathbf{g} / \mathbf{k g})\end{array}$ \\
\hline Casein & 200 & 186 & 186 & 187 \\
DL-Methionine & 3 & 3 & 3 & 3 \\
Sucrose & 499.99 & 499.9 & 499.99 & 499.99 \\
Corn Starch & 150 & - & - & - \\
Corn Oil & 50 & 50 & 46.5 & 46 \\
Cellulose & 50 & 50 & 50 & 50 \\
Mineral Mix, AIN-76 (170915) & 35 & 35 & 35 & 35 \\
Vitamin Mix, AIN-76A (40077) & 10 & 10 & 10 & 10 \\
Choline Bitartrate & 2 & 2 & 2 & 2 \\
Ethoxyquin, antioxidant & 0.01 & 0.01 & 0.01 & 0.01 \\
Freeze dried cooked white rice & - & $170 *$ & - & - \\
Freeze dried cooked brown rice & - & - & $175^{*}$ & - \\
Freeze dried cooked parboiled germinated & - & - & & $175^{*}$ \\
brown rice & - & - & & \\
\hline
\end{tabular}

Note: *The contents of freeze dried cooked white rice, brown rice and parboiled germinated brown rice added into the diet were based on the composition of energy, protein, carbohydrate and fat.

\section{Experimental design}

After the acclimation, 35 male Sprague-Dawley rats were divided into five groups of seven each. The control rats in Group I were fed with the basal diet. The rats in Group II were fed with the basal diet $\left(\mathrm{CCl}_{4}\right.$ group). The rats in Groups III, IV, and V were fed with white rice ( $\mathrm{WR}+\mathrm{CCl}_{4}$ group), brown rice $(\mathrm{BR}+$ $\mathrm{CCl}_{4}$ group), and PGBR (PGBR $+\mathrm{CCl}_{4}$ group) diet, respectively. The rats in Group II, III, IV, and IV were orally administrated with $1 \mathrm{~mL}$ of $\mathrm{CCl}_{4} /$ olive oil mixture $(1: 1, \mathrm{v} / \mathrm{v}) / \mathrm{kg}$ of body weight twice a week for the duration of the eightweek experiment. All the rats were allowed ad libitum access to the experimental diets and water. When the eight-week period was completed, the rats underwent one night of fasting prior to euthanasia with carbon dioxide anaesthesia. Samples of the rats' brains were then placed immediately in liquid nitrogen in order to store them at $-80{ }^{\circ} \mathrm{C}$ prior to examination.

\section{Liver function tests}

An automated clinical chemistry analyser (HITACHI 902; Roche Diagnostics Co., Indiana, IN, USA) was used to determine the levels of the serum of aspartate aminotransferase (AST), alanine aminotransferase (ALT), and alkaline phosphatase (ALP). 


\section{Blood ammonia level}

The blood samples were collected by cardiac puncture and then centrifuged to obtain the plasma. The plasma ammonia measurement was performed enzymatically (Gebhardt and Reichen, 1994).

\section{Preparation of the brain homogenate}

Brain homogenisation (cerebral cortex, hippocampus and cerebellum) was performed using a manual homogeniser with an ice-cold Tris-HCl buffer (100 $\mathrm{mmol} / \mathrm{L}, \mathrm{pH} 7.4)$ containing $5 \mathrm{mmol} / \mathrm{L}$ EDTA and $1 \%(\mathrm{v} / \mathrm{v})$ of Triton X-100 to give a final concentration of $10 \% \mathrm{w} / \mathrm{v}$. The homogenised brain was sonicated on ice for 10 minutes and centrifuged at 3,000x g for 10 minutes at $4{ }^{\circ} \mathrm{C}$ (ROTINA 38 , Tuttlingen, Germany). The supernatant was collected and stored at $-80{ }^{\circ} \mathrm{C}$. The protein content assay was determined by a bicinchoninic acid (BCA) protein assay (Smith et al., 1985) using bovine serum albumin (BSA) (Bio-Rad Laboratories, CA, USA) as a standard and using a Synergy ${ }^{\mathrm{TM}}$ HT microplate reader (BioTek, Vermont, USA) for detection.

\section{Measuring the cytokines}

The content of the tumour necrosis factor alpha (TNF- $\alpha$ ) in each region of brain was determined using a commercial TNF- $\alpha$ ELISA kit (eBioscience Inc., San Diego, CA, USA). The content of interleukin 6 (IL-6) and interleukin 1 beta (IL-1 $\beta$ ) in each region of brain were determined using ELISA kits (ImmunoBiological Laboratories Co., Ltd., Gunma, Japan).

\section{Statistical analysis}

Data presentation was in the form of the mean \pm standard error for the seven rats. A statistical significance level of 0.05 was used for the Tukey tests and one-way analysis of variance.

\section{RESULTS}

\section{Different diet effects on the serum liver function indices in rats treated with $\mathrm{CCl}_{4}$}

Serum AST, ALT and ALP are biomarkers of liver function, which can reflect liver injury. $\mathrm{CCl}_{4}$-treated rats significantly increased in the serum activities of AST, ALT, and ALP when compared to the control group. However, the activities of AST and ALT of the PGBR $+\mathrm{CCl}_{4}$ group were significantly lower than that of the $\mathrm{CCl}_{4}$ group by $40.2 \%$ and $30 \%$, respectively, as indicated in Figure 1. 

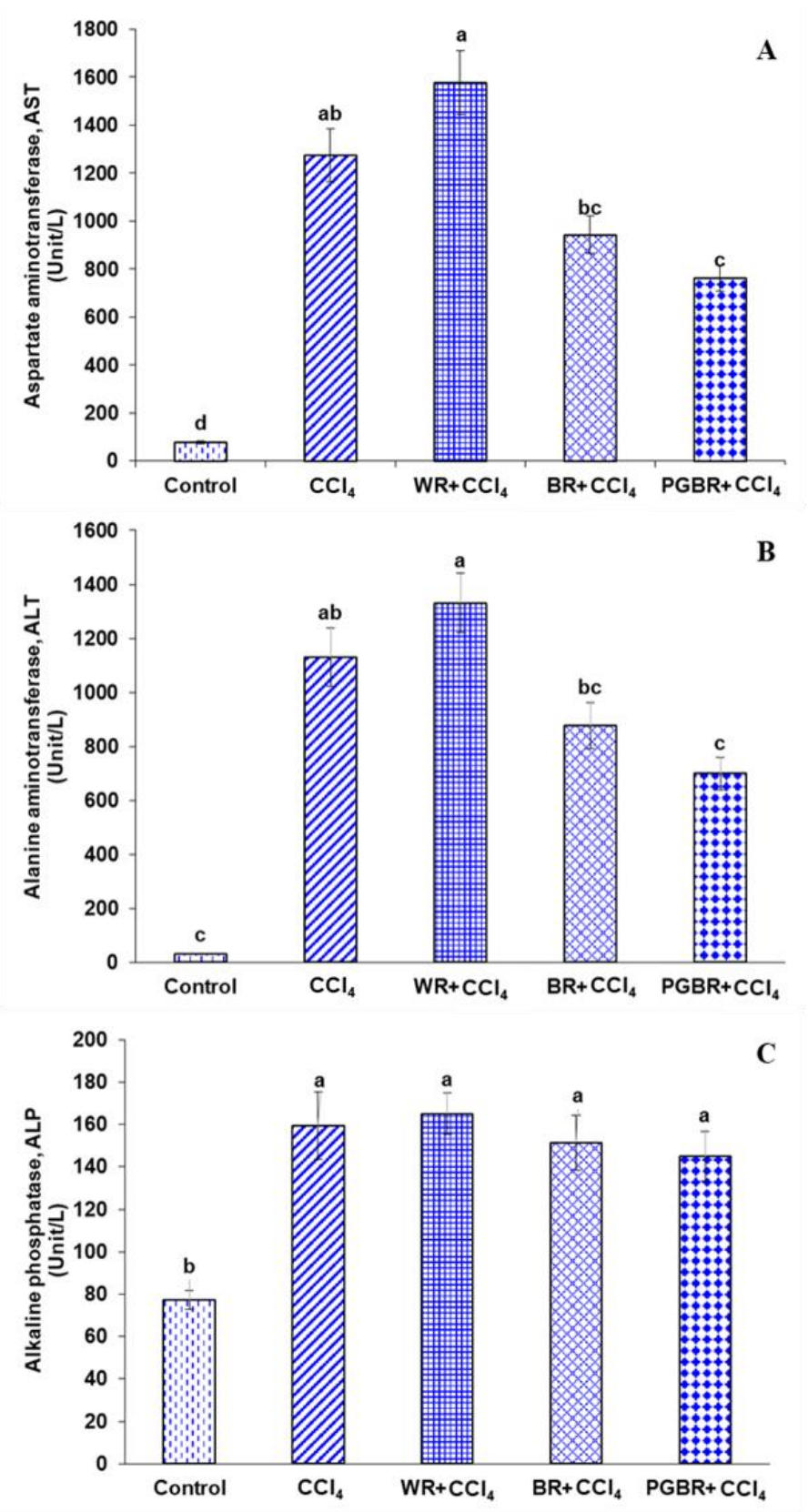

Figure 1. Liver functions in all groups. (A) aspartate aminotransferase (AST). (B) alanine aminotransferase (ALT). (C) alkaline phosphatase (ALP). Data are presented as means \pm SE. Number of animals in each group $(n)=7$. Means with different superscripts $(a, b, c, d)$ in each bar are significantly different $(P<0.05)$.

\section{Different diet effects on plasma ammonia levels in rats treated with}

\section{$\mathrm{CCl}_{4}$}

As illustrated in Figure 2, the blood ammonia level in the $\mathrm{CCl}_{4}$ group was significantly elevated as compared to the control group. The $\mathrm{BR}+\mathrm{CCl}_{4}$ and $\mathrm{PGBR}+\mathrm{CCl}_{4}$ group were significantly lower than the $\mathrm{CCl}_{4}$ group by $29.8 \%$ and $36.9 \%$, respectively. 


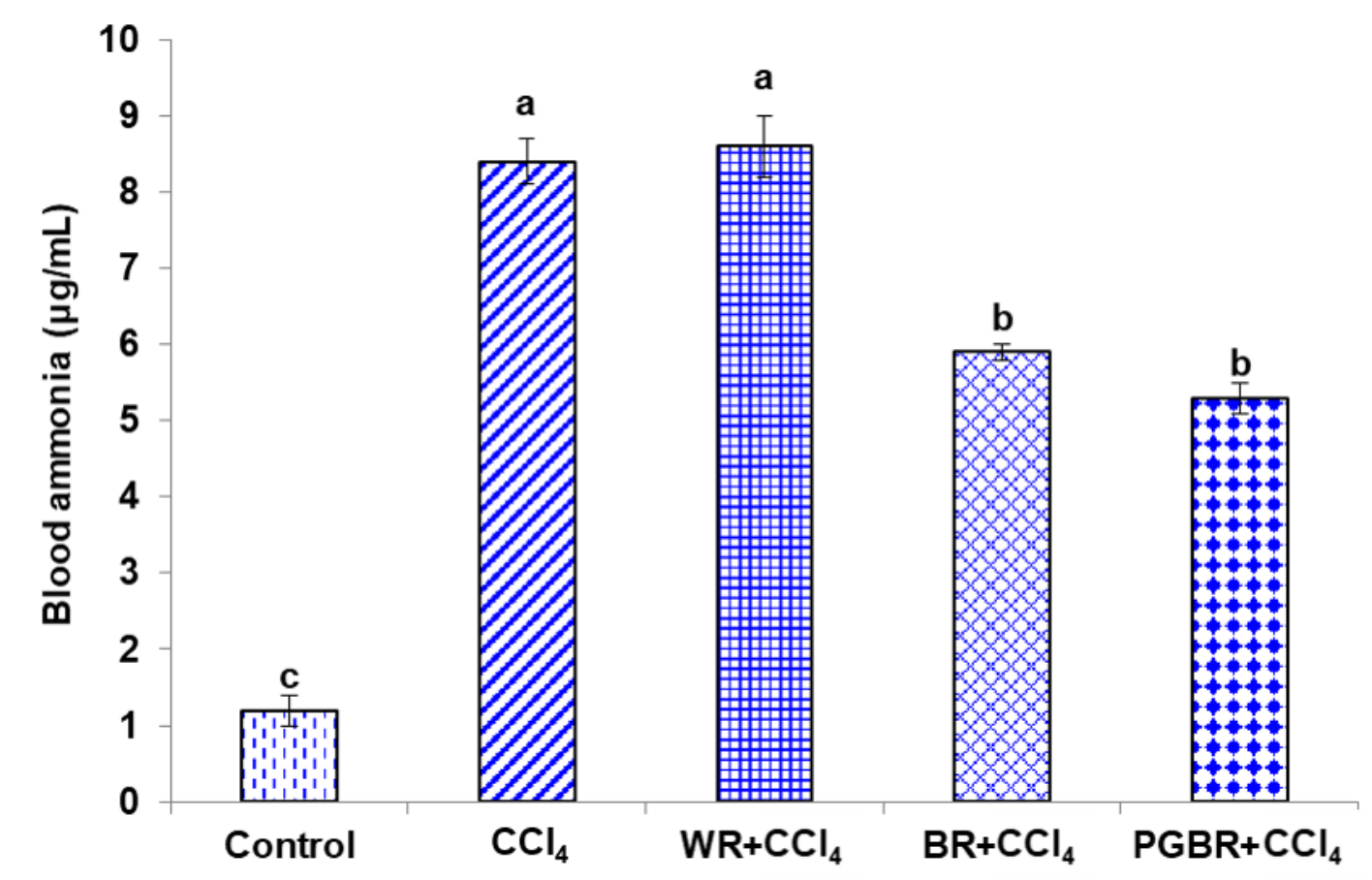

Figure 2. The level of blood ammonia in $\mathrm{CCl}_{4}{ }^{-}$treated rats. Data are presented as means $\underline{ \pm}$ SE. Number of animals in each group $(n)=7$. Means with different superscripts $(a, b, c)$ in each bar are significantly different $(P<0.05)$.

Different diet effects on the TNF- $\alpha$ levels in the various regions of the brain in rats treated with $\mathrm{CCl}_{4}$

As illustrated in Figure 3, brain inflammation induced by $\mathrm{CCl}_{4}$ provoked a significant increase in the TNF- $\alpha$ level of the cortex, hippocampus and cerebellum of $\mathrm{CCl}_{4}$-treated rat groups in comparison with the control group. However, the level of TNF- $\alpha$ in the PGBR $+\mathrm{CCl}_{4}$ group was significantly decreased in the cortex, hippocampus and cerebellum by $36.4 \%, 38.9 \%$ and $36.4 \%$, respectively when compared to the $\mathrm{CCl}_{4}$ group $(P<0.05)$. Interestingly, the PGBR+CCl${ }_{4}$ group showed a significant decrease of the TNF- $\alpha$ level in the hippocampus and cerebellum when compared to the $\mathrm{CCl}_{4}, \mathrm{WR}+\mathrm{CCl}_{4}$ and $\mathrm{BR}+\mathrm{CCl}_{4}$ groups. 

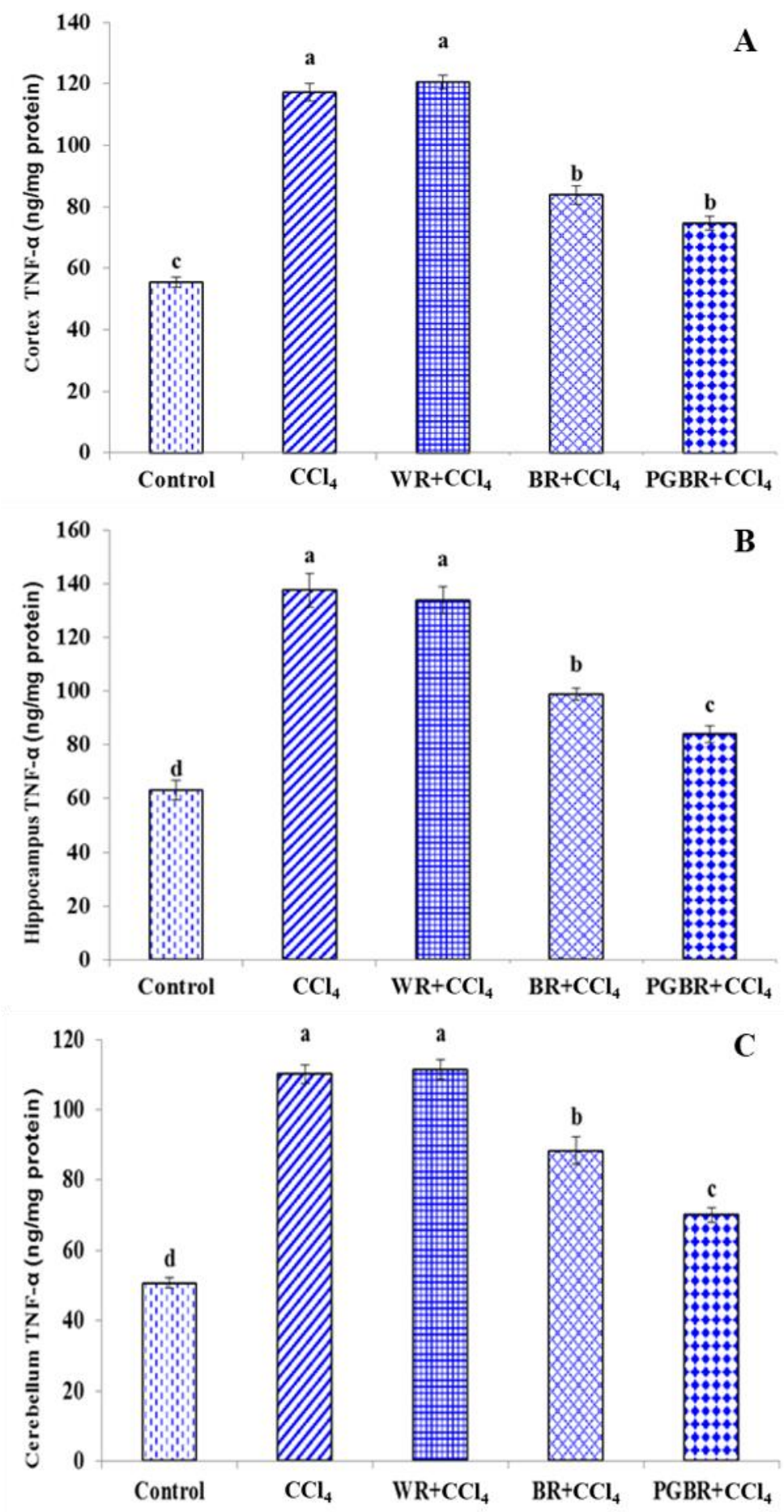

Figure 3. The TNF- $\alpha$ level in brain contex (A), hippocampus (B) and cerebellum (C) in $\mathrm{CCl}_{4}^{-}$treated rats. Data are presented as means \pm SE. Number of animals in each group $(n)=7$. Means with different superscripts $(\mathrm{a}, \mathrm{b}, \mathrm{c}, \mathrm{d})$ in each bar are significantly different $(P<0.05)$ 


\section{Different diet effects on the IL-1 $\beta$ levels in the various regions of the}

\section{brain in rats treated with $\mathrm{CCl}_{4}$}

To evaluate the brain inflammatory markers, the IL- $1 \beta$ level of the cortex, hippocampus and cerebellum was also examined. IL-1 $\beta$ is a pro-inflammatory cytokine that has been implicated in inflammation, pain and autoimmune conditions. As shown in Figure 4, a significant increase in the IL-1 $\beta$ level was observed in all areas of the brain in $\mathrm{CCl}_{4}$-treated rats compared to those of the control group $(P<0.05)$. However, the level of IL-1 $\beta$ in the brain cortex, hippocampus and cerebellum of the $\mathrm{PGBR}+\mathrm{CCl}_{4}$ group was significantly decreased by $34.7 \%, 28.4 \%$ and $29.9 \%$, respectively when compared to the $\mathrm{CCl}_{4}$ group $(P<0.05)$.

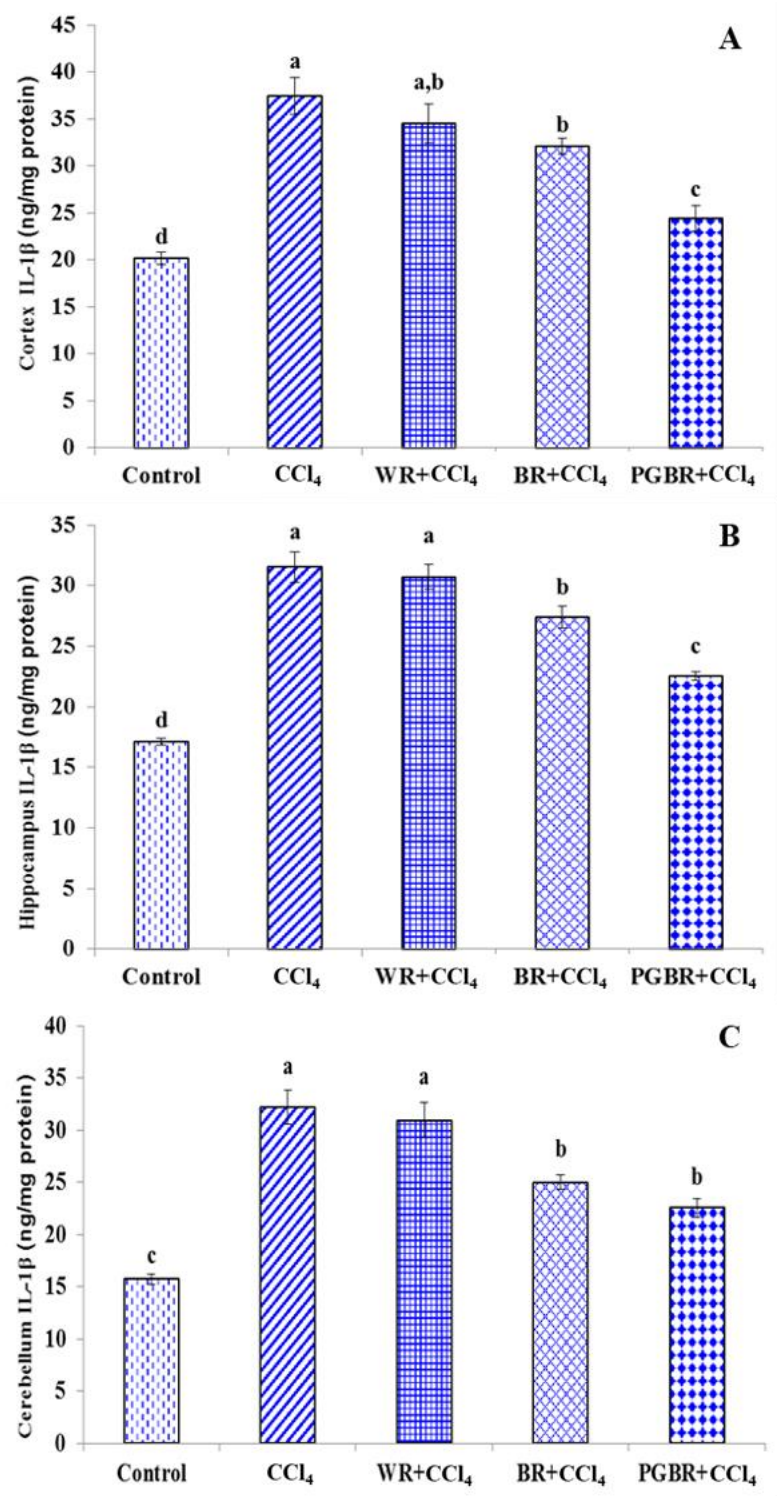

Figure 4. The IL-1 $\beta$ level in brain contex (A), hippocampus (B) and cerebellum (C) in $\mathrm{CCl}_{4}{ }^{-}$treated rats. Data are presented as means \pm SE. Means with different superscripts (a, b, c, d) in each bar are significantly different $(P<0.05)$. 


\section{Different diet effects on the IL-6 levels in the various regions of the brain in rats treated with $\mathrm{CCl}_{4}$}

The level of IL-6 in the cortex, hippocampus and cerebellum was also analyzed to evaluate brain inflammation (Figure 5). The IL-6 levels increased significantly in all areas of the brain in the $\mathrm{CCl}_{4}$ group when compared to the control group $(P<0.05)$. The $\mathrm{WR}+\mathrm{CCl}_{4}$ and $\mathrm{BR}+\mathrm{CCl}_{4}$ groups had no significant difference in the IL-6 levels of the cortex and hippocampus when compared to the $\mathrm{CCl}_{4}$ group. Nonetheless, the IL-6 levels of the cortex and hippocampus of the PGBR+CCl ${ }_{4}$ group were significantly lower by $23 \%$ and $16.3 \%$, respectively when compared to that of the $\mathrm{CCl}_{4}$ group. However, in the case of the cerebellum, all the rats fed with rice diets had no significant difference in the IL-6 level when compared to the $\mathrm{CCl}_{4}$ group.

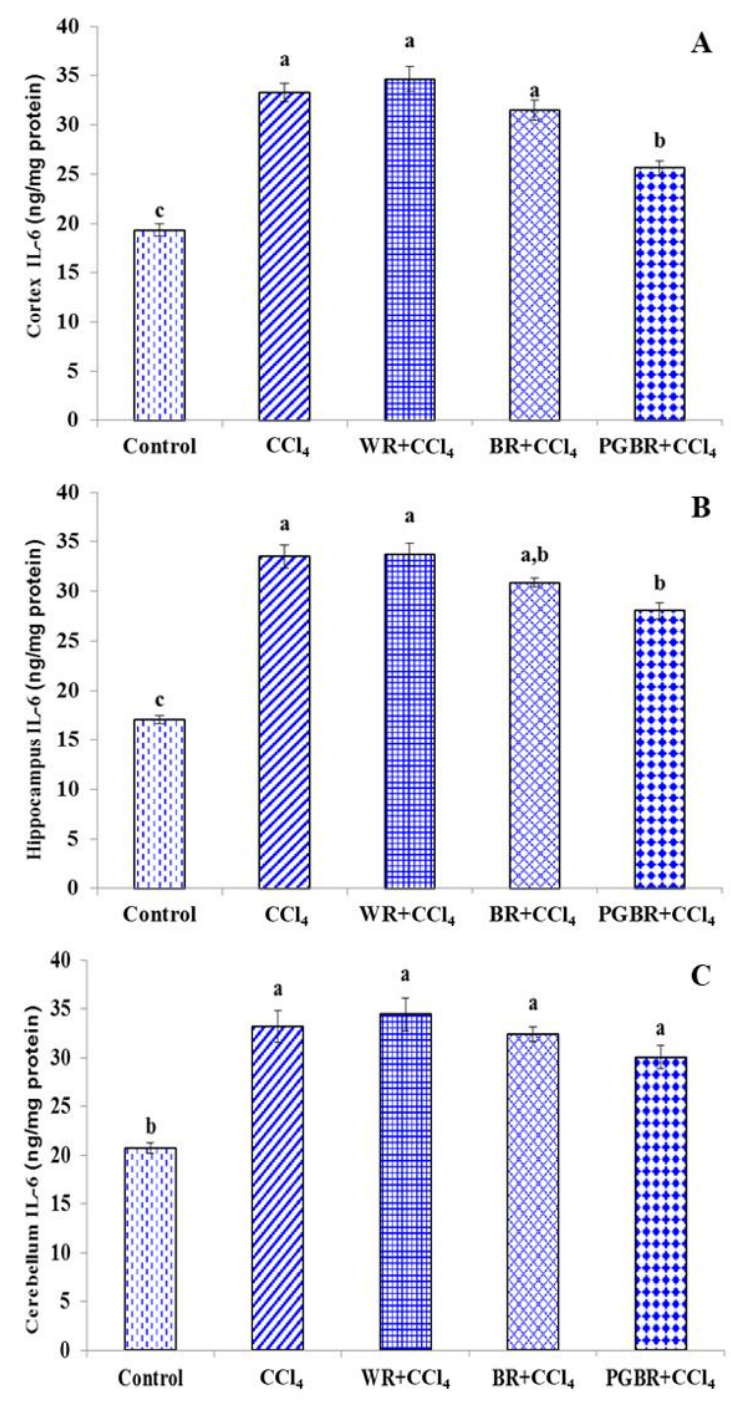

Figure 5. The IL-6 level in brain contex (A), hippocampus (B) and cerebellum (C) in $\mathrm{CCl}_{4}{ }^{-}$treated rats. Data are presented as means \pm SE. Means with different superscripts $(\mathrm{a}, \mathrm{b}, \mathrm{c})$ in each bar are significantly different $(P<0.05)$. 


\section{DISCUSSION}

Neuroinflammation is a process that has received increased attention in neurodegenerative diseases; such as Alzheimer's and Parkinson's disease, and has also been found in hepatic encephalopathy, which participates in more subtle neurological manifestations of liver disease (Butterworth, 2011). The liver plays a vital role in most metabolic processes. One of these processes is the detoxification of ammonia in the blood. The increase in blood ammonia in advanced liver disease is a consequence of impaired liver function. Elevated ammonia causes sudden swelling and inflammation of the brain, as well as brain function may deteriorate after acute liver failure. (Rao et al., 2010; Back et al., 2011; Rao et al., 2013).

According to the results of this study, $\mathrm{CCl}_{4}$-treated rats showed a significant increase in the serum AST, ALT and ALP, biomarkers of liver damage, and blood ammonia when compared to the control group. Moreover, the present study revealed that after the rats were treated with $\mathrm{CCl}_{4}$ for eight weeks, the inflammatory cytokines including TNF- $\alpha$, IL- $1 \beta$ and IL- 6 increased markedly in all areas of the brain including the cerebral cortex, hippocampus and cerebellum. However, the study of de Souza Machado et al. (2015) demonstrated that male Wistar rats received a single intraperitoneal injection of $\mathrm{CCl}_{4}$ in a dose of $3.0 \mathrm{~mL} / \mathrm{kg}$ induced the increase of TNF- $\alpha$, IL-1 $\beta$ and IL-18 levels in the cerebral cortex, hippocampus and cerebellum, whereas the IL- 6 and IL-10 brain tissues levels remained unchanged during all treatments.

Since $\mathrm{CCl}_{4}$ is a lipid soluble, it is capable of passing through membranes to form deposits in a wide range of bodily tissues, especially the liver and brain (Dashti et al., 1989). $\mathrm{CCl}_{4}$ can be activated by the cytochrome P450 enzyme, especially CYP2E1, to form the trichloromethyl radical $\mathrm{CCl}_{3}{ }^{\bullet}$ and the trichloromethyl peroxy radical $\mathrm{CCl}_{3} \mathrm{OO} \cdot$, leading to oxidative stress and cell injury (Dashti et al., 1989; Bhagwat et al., 1995; Boer et al., 2009). Microglia become activated under brain injury and release the pro-inflammatory cytokines IL- $1 \alpha$, IL- $1 \beta$ and TNF- $\alpha$; all of which play a crucial role in brain pathology (Cagnin et al., 2006; Rovira et al., 2007; García Martínez et al., 2010).

Interestingly, the authors found that rats fed with PGBR had significantly reduced serum levels of ALT, AST, ALP and blood ammonia. In accordance with these results, the present study also found that PGBR prevented the $\mathrm{CCl}_{4}$-induced increase of the pro-inflammatory cytokines TNF- $\alpha$ and IL- $1 \beta$ in the rat's cerebral cortex, hippocampus and cerebellum, as well as IL-6 in the cerebral cortex and hippocampus. The abundant bioactive compounds found in PGBR; such as, ferulic acid, $p$-coumaric acid, $\gamma$-oryzanol and $\gamma$-tocotrienol, were present at higher concentrations in PGBR than in white rice and brown rice (Wunjuntuk et al., 2016b). It has been reported that these compounds have the potential to act as an antioxidant, which may suppress free radicals generated in the liver and brain of rats induced by CYP2E1-metabolised $\mathrm{CCl}_{4}$ (Kamal-Eldin and Appelqvist, 1996; 
Abdel Wahab et al., 2003; Cheng et al., 2008; Kim et al., 2011; Saenjum et al., 2012). In addition, GABA, which was dramatically increased during the germination of PGBR, may regulate the glutamatergic system by enhancing the release of glutamate and the sensitivity of the NMDA receptors resulting in memory enhancement (Zhang et al., 2010). A previous study by Hou (2011) reported that GABA prevented kainic acid (KA)-induced neuronal injury by suppressing lipid peroxidation in male FVB mice brains and inhibiting ROS accumulation in the rat's pheochromocytoma cell line (PC12). Moreover, Shilpa et al. (2014) revealed that treatment of GABA and serotonin (5-HT) chitosan nanoparticles in partially hepatectomised rats were able to protect the neurons from ROS mediated cell damage and promoted their survival in the cerebral cortex by means of the regulation of the gene expression of NF- $\kappa \mathrm{B}, \mathrm{TNF}-\alpha$, and superoxide dismutase (SOD). Therefore, the several bioactive compounds found in PGBR may suppress $\mathrm{CCl}_{4}$-induced liver and brain oxidative damage contributing to the inhibition of brain inflammation. However, the molecular mechanisms of the results need to be ascertained in further studies.

\section{CONCLUSION}

These findings revealed that PGBR could help to prevent brain pathology associated with brain inflammation induced by liver failure or oxidative stress.

\section{ACKNOWLEDGEMENTS}

A research grant from the Agricultural Research Development Agency (Public Organization), Thailand, was used to fund this study under the assigned Research No.2555NRCT512316. The authors would like to extend their thanks to the Faculty of Pharmaceutical Science, Prince of Songkla University, for their provision of the carbon tetrachloride used in the study, and to RCK Agri Marketing Co., Ltd., Thailand for the rice.

\section{REFERENCES}

Abdel Wahab, M.H., El Mahdy, M.A., Abd Ellah, M.F., Helal, G.K., Khalifa, F., and Hamada, F.M. 2003. Influence of $p$-coumaric acid on doxorubicininduced oxidative stress in rat's heart. Pharmacological Research. 48(5): 461-465. https://doi.org/10.1016/S1043-6618(03)00214-7

Atanassov, C.L., Muller, C.D., Sarhan, S., Knödgen, B., Rebel, G., and Seiler, N. 1994. Effect of ammonia on endocytosis, cytokine production and lysosomal enzyme activity of a microglial cell line. Research in Immunology. 145(4): 277-288. https://doi.org/10.1016/S0923-2494(94) 80016-2 
Back, A., Tupper, K.Y., Bai, T., Chiranand, P., Goldenberg, F.D., Frank, J.I., and Brorson, J. R. 2011. Ammonia-induced brain swelling and neurotoxicity in an organotypic slice model. Neurological Research. 33(10): 1100-1108. https://doi.org/10.1179/1743132811Y.0000000046

Bhagwat, S.V., Boyd, M.R., and Ravindranath, V. 1995. Brain mitochondrial cytochromes P450: xenobiotic metabolism, presence of multiple forms and their selective inducibility. Archives of Biochemistry and Biophysics. 320(1): 73-83. https://doi.org/10.1006/abbi.1995.1344

Boer, L.A., Panatto, J.P., Fagundes, D.A., Bassani, C., Jeremias, I.C., Daufenbach, J.F., Rezin, G.T., Constantino, L., Dal-Pizzol, F., and Streck, E.L. 2009. Inhibition of mitochondrial respiratory chain in the brain of rats after hepatic failure induced by carbon tetrachloride is reversed by antioxidants. Brain Research Bulletin. 80: 75-78. https://doi.org/10. 1016/j.brainresbull.2009.04.009

Butterworth, R.F. 2011. Hepatic encephalopathy: a central neuroinflammatory disorder. Hepatology. 53(4): 1372-1376. https://doi.org/10.1002/hep. 24228

Cagnin, A., Taylor-Robinson, S.D., Forton, D.M., and Banati, R.B. 2006. In vivo imaging of cerebral 'peripheral benzodiazepine binding sites' in patients with hepatic encephalopathy. Gut. 55(4): 547-553. https://doi.org/10. 1136/gut.2005.075051

Cheng, C.Y., Ho, T.Y., Lee, E.J., Su, S.Y., Tang, N.Y., and Hsieh, C.L. 2008. Ferulic acid reduces cerebral infarct through its antioxidative and antiinflammatory effects following transient focal cerebral ischemia in rats. The American Journal of Chinese Medicine. 36: 1105-1119. https://doi. org/10.1142/S0192415X08006570

Dashti, H., Jeppsson, B., Hagerstrand, I., Hultberg, B., Srinivas, U., Abdulla, M., and Bengmark, S. 1989. Thioacetamide- and carbon tetrachloride-induced liver cirrhosis. European Surgical Research. 21: 83-91. https://doi.org/ $10.1159 / 000129007$

de Souza Machado, F., Marinho, J.P., Abujamra, A.L., Dani, C., QuincozesSantos, A., and Funchal, C. 2015. Carbon tetrachloride increases the proinflammatory cytokines levels in different brain areas of wistar rats: the protective effect of acai frozen pulp. Neurochemical Research. 40(9): 1976-1983. https://doi.org/10.1007/s11064-015-1693-z

García Martínez, R., Rovira, A., Alonso, J., Aymerich, F.X., Huerga, E., Jacas, C., Simón-Talero, M., Vargas, V., and Córdoba, J. 2010. A longterm study of changes in the volume of brain ventricles and white matter lesions after successful liver transplantation. Transplantation. 89: 589-594. https://doi.org/10.1097/TP.0b013e3181ca7bb3 
Gebhardt, R., and Reichen, J. 1994. Changes in distribution and activity of glutamine synthetase in carbon tetrachloride-induced cirrhosis in the rat: potential role in hyperammonemia. Hepatology. 20(3): 684-691. https:// doi.org/10.1002/hep.1840200320

Hou, C.W. 2011. Pu-Erh tea and GABA attenuates oxidative stress in kainic acidinduced status epilepticus. Journal of Biomedical Science. 18(1): 75. https://doi.org/10.1186/1423-0127-18-75

Imam, M.U., Azmi, N.H., Bhanger, M.I., Ismail, N., and Ismail, M. 2012. Antidiabetic properties of germinated brown rice: a systematic review. Evidence-Based Complementary and Alternative Medicine. 2012:816501. https://doi.org/10.1155/2012/816501

Jayakumar, A.R., Panickar, K.S., Murthy, Ch.R., and Norenberg, M.D. 2006. Oxidative stress and mitogen-activated protein kinase phosphorylation mediate ammonia-induced cell swelling and glutamate uptake inhibition in cultured astrocytes. Journal of Neuroscience. 26: 4774-4784. https://doi. org/10.1523/JNEUROSCI.0120-06.2006

Kamal-Eldin, A., and Appelqvist, L.A. 1996. The chemistry and antioxidant properties of tocopherols and tocotrienols. Lipids. 31(7): 671-701. https://doi.org/10.1007/bf02522884

Kayahara, H., and Tsukahara K. 2000. Flavor, health and nutritional quality of pregerminated brown rice. Proceeding of the International Chemical Congress of Pacific Basin Societies. Honolulu, Hawaii, USA. p. 546-551.

Kim, H.Y., Park, J., Lee, K.H., Lee, D.U., Kwak, J.H., Kim, Y.S., and Lee, S.M. 2011. Ferulic acid protects against carbon tetrachloride-induced liver injury in mice. Toxicology. 282(3): 104-111. https://doi.org/10.1016/ j.tox.2011.01.017

Latifah, S.Y., Armania, N., Tze, T.H., Azhar, Y., Nordiana, A.H., Norazalina, S., Hairuszah, I., Saidi, M., and Maznah, I. 2010. Germinated brown rice reduces the incidence of aberrant crypt foci with the involvement of $\beta$ catenin and COX-2 in azoxymethane-induced colon cancer in rats. Nutrition Journal. 9:16. https://doi.org/10.1186/1475-2891-9-16

Preston, A.R., and Eichenbaum, H. 2013. Interplay of hippocampus and prefrontal cortex in memory. Current Biology. 23(17): R764-773. https://doi.org/10.1016/j.cub.2013.05.041

Rao, K.V., Brahmbhatt, M., and Norenberg, M.D. 2013. Microglia contribute to ammonia-induced astrocyte swelling in culture. Metabolic Brain Disease. 28: 139-143. https://doi.org/10.1007/s11011-012-9339-1

Rao, K.V., Jayakumar, A.R., Tong, X., Alvarez, V.M., and Norenberg, M.D. 2010. Marked potentiation of cell swelling by cytokines in ammoniasensitized cultured astrocytes. Journal of Neuroinflammation. 7: 66. 
Rovira, A., Mínguez, B., Aymerich, F.X., Jacas, C., Huerga, E., Córdoba, J., and Alonso, J. 2007. Decreased white matter lesion volume and improved cognitive function after liver transplantation. Hepatology. 46: 1485-1490. https://doi.org/10.1002/hep.21911

Saenjum, C., Chaiyasut, C., Chansakaow, S., Suttajit, M., and Sirithunyalug, B. 2012. Antioxidant and anti-inflammatory activities of gamma-oryzanol rich extracts from Thai purple rice bran. Journal of Medicinal Plants Research. 6: 1070-1077. https://doi.org/10.5897/JMPR11.1247

Shilpa, J., Anju, T.R., Ajayan, M.S., and Paulose, C.S. 2014. Increased cortical neuronal survival during liver injury: effect of gamma aminobutyric acid and 5-HT chitosan nanoparticles. Journal of Biomedical Nanotechnology. 10(4): 622-631. https://doi.org/10.1166/jbn.2014.1762

Smith, P.K., Krohn, R.I., Hermanson, G.T., Mallia, A.K., Gartner, F.H., Provenzano, M.D., Fujimoto, E.K., Goeke, N.M., Olson, B.J., and Klenk, D.C. 1985. Measurement of protein using bicinchoninic acid. Analytical Biochemistry. 150: 76-85. https://doi.org/10.1016/0003-2697 (85)90442-7

Soiampornkul, R., Junnu, S., Kanyok, S., Liammongkolkul, S., Katanyoo, W., and Umpornsirirat, S. 2012. Antioxidative and neuroprotective activities of the pre-germinated brown rice extract. Food and Nutrition Sciences. 3: 135-140. https://doi.org/10.4236/fns.2012.31020

Wunjuntuk, K., Kettawan, A., Charoenkiatkul, S., and Rungruang, T. $2016 a$. Parboiled germinated brown rice protects against $\mathrm{CCl}_{4}$-induced oxidative stress and liver injury in rats. Journal of Medicinal Food. 19(1): 15-23. https://doi.org/10.1089/jmf.2015.3460

Wunjuntuk, K., Kettawan, A., Rungruang, T., and Charoenkiatkul, S. 2016 b. Anti-fibrotic and anti-inflammatory effects of parboiled germinated brown rice (Oryza Sativa 'KDML 105') in rats with induced liver fibrosis. Journal of Functional Foods. 26:363-372. https://doi.org/10.1016/j.jff.2016.08.009

Yamamoto, H., and Sugihara, N. 1987. Blood ammonia levels and hepatic encephalopathy induced by $\mathrm{CCl}_{4}$ in rats. Toxicology and Applied Pharmacology. 91(3): 461-468. https://doi.org/10.1016/00411-008X(87) 90067-6

Zhang, R., Lu, H., Tian, S., Yin, J., Chen, Q., Ma, L., Cui, S., and Niu, Y. 2010. Protective effects of pre-germinated brown rice diet on low levels of $\mathrm{Pb}$-induced learning and memory deficits in developing rat. ChemicoBiological Interactions. 184(3): 484-491. https://doi.org/10.1016/j.cbi. 2010.01.043 